\title{
EL RETABLO MAYOR DEL MONASTERIO JERÓNIMO DE SANTA MARÍA DE ESPEJA. UNA VIEJA IMAGEN Y UNA NUEVA VISIÓN
}

\author{
JUAN MARÍA CRUZ YÁBAR \\ Conservador. Museo Arqueológico Nacional
}

Realizamos un estudio del retablo de Giovanni Battista Crescenzi para el monasterio jerónimo de Espeja sobre la base de una antigua imagen que hasta ahora no era conocida por los especialistas. Se compara con otras obras de Crescenzi y con el retablo diseñado por Juan Gómez de Mora para el hospital de Antón Martín, y se obtienen conclusiones acerca de las similitudes y diferencias, representativas de los gustos estéticos de ambos. La fotografía permite observar dos pinturas de Juan Bautista Maíno, de las seis que hizo para este retablo.

Palabras clave: Monasterio de Espeja; Retablos; Giovanni Battista Crescenzi; Fray Juan Bautista Maíno.

\section{THE MAIN ALTARPIECE OF THE JERONYMITE MONASTERY OF SANTA MARÍA DE ESPEJA: AN OLD IMAGE AND A NEW VISION}

This study deals with the altarpiece by Giovanni Battista Crescenzi for the Jeronymite Monastery of Espeja, by using an old image unknown to specialists until now. The author compares this work to others by Crescenzi, as well as to the altarpiece designed by Juan Gómez de Mora for the Hospital of Antón Martin, thereby arriving at conclusions concerning their similarities and differences, representative of their aesthetic tastes. The photograph likewise reveals two of the six paintings by Juan Bautista Maíno for this altarpiece. Maíno.

Key words: Monastery of Espeja; Altarpieces; Giovanni Battista Crescenzi; Brother Juan Bautista

Un estudio de 1956 de Florentino Zamora Lucas daba por desaparecido el retablo del monasterio jerónimo de Espeja de San Marcelino (Soria) en Alcalá de Henares durante la Guerra Civil, suponiendo que había sido trasladado allí con motivo de la Desamortización. Demostramos que no fue así, porque existe una fotografía del siglo XX donde aparece en el monasterio jerónimo para el que fue hecho ${ }^{1}$. La fotografía muestra la estructura íntegra y en muy buen estado de con-

${ }^{1}$ La fotografía se conserva en el Archivo Histórico Provincial de Soria sin detallar el año en que fue tomada, y deducimos que tiene que ser anterior a 1932, que fue cuando se trasladó el sepulcro de don Diego de Avellaneda, obis- 


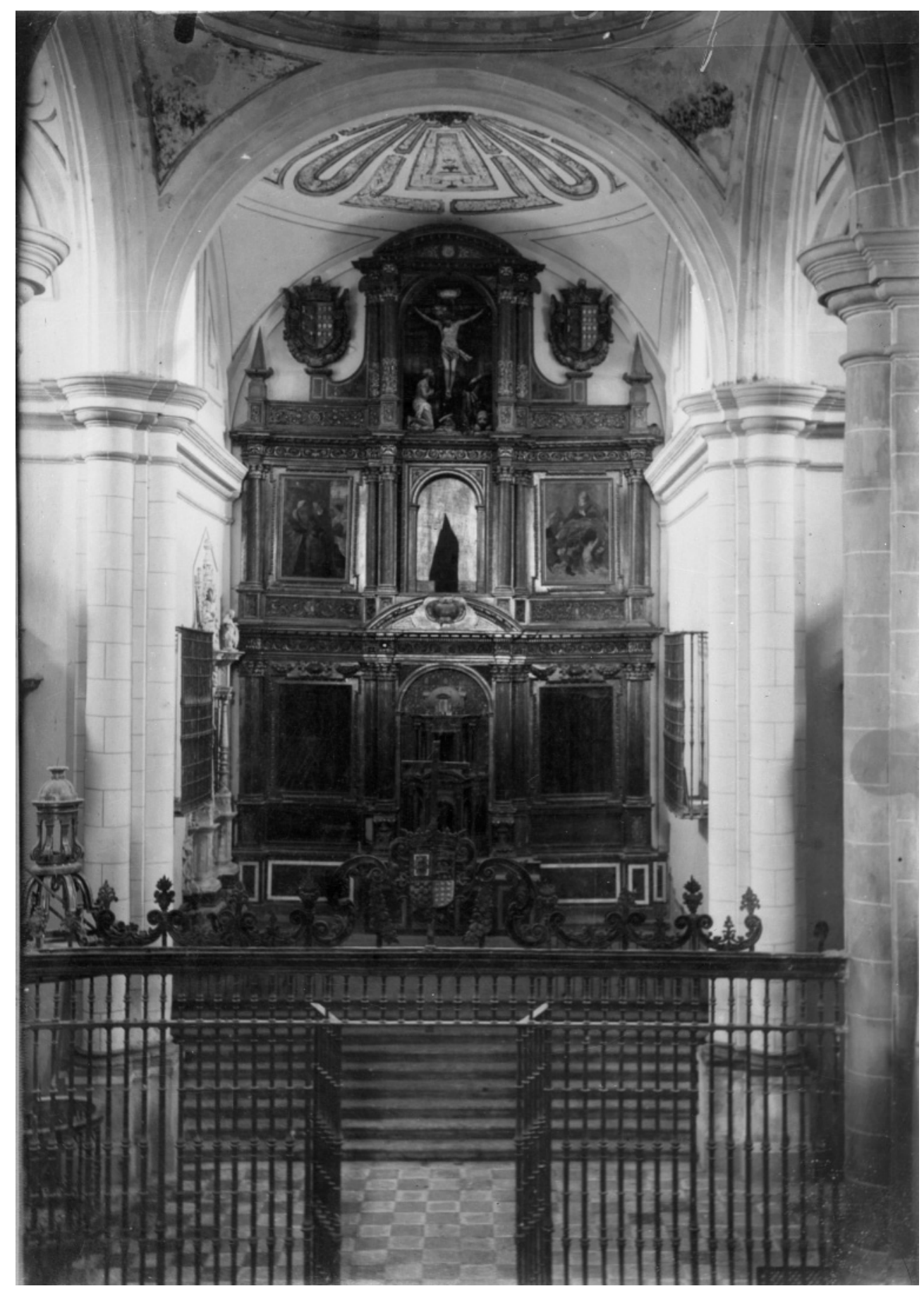

Fig. 1. Retablo mayor del monasterio de Espeja (desaparecido). Fotografía del Archivo Histórico Provincial de Soria. 
servación, pese a la pérdida de cuatro de sus pinturas y de las tallas de los cuerpos inferiores. Ninguno de los investigadores que hasta ahora se ha ocupado de esta obra ha sabido de la existencia de tal imagen, cuya importancia se acrecienta al tratarse del único retablo cuyo aspecto conocemos hecho por traza de Giovanni Battista Crescenzi, marqués de la Torre, y por contener dos lienzos de fray Juan Bautista Maíno. Repasamos a continuación las noticias publicadas en torno a la capilla mayor del monasterio de Espeja y su retablo, y aportamos nuestra visión tras examinar los documentos referentes a esta obra en relación con su verdadero aspecto.

Agulló proporcionó en 1978 la primera noticia documental acerca de la hechura de un retablo para el monasterio de Espeja, con una breve referencia a un contrato de 1635 suscrito por el ensamblador Martín Martínez y el entallador Isidro Cabezón de Salas, ambos vecinos de Madrid, por el que el segundo se obligaba a labrar la talla de un retablo que se había encargado a Martínez con destino a este cenobio ${ }^{2}$. En otra recopilación de ese mismo año dio a conocer un testamento del dorador Simón López en que declaraba que tenía hecha compañía con Miguel de Viveros para la obra de San Jerónimo de Espeja que era del señor conde de Castrillo ${ }^{3}$. Una vez pagados los oficiales, las cuentas arrojaban una deuda de 200 ducados a favor de cada uno de los maestros y López daba orden para su cobro.

Estas referencias de archivo fueron utilizadas por primera vez, aunque sin profundizar en su contenido, por Belén Bartolomé ${ }^{4}$, en un trabajo cuyo objeto era examinar los gustos artísticos de don García de Haro y Avellaneda, II conde de Castrillo y presidente por entonces del Consejo de Indias. Precisó que los datos de Agulló se referían al retablo mayor de la iglesia monacal, de cuya capilla mayor era patrono el conde, y adjudicó a Martín Martínez el papel de supervisor de la obra y a Isidro Cabezón el de realizador, lo que no es exacto. Localizó además el contrato de Martínez para el retablo mayor, en el cual se especificaba que la traza se debía a Giovanni Battista Crescenzi, marqués de la Torre y superintendente de las obras reales. Reveló también - sin indicar la referencia documental- que contenía tres esculturas encomendadas a Jorge Capitán, y citó los nombres del ensamblador Alberto Ribero y el carpintero Antonio Rojo como artífices que intervinieron en la obra, aunque en realidad sólo actuaron como fiadores.

Pérez Sánchez, en un artículo de 1997 dedicado al pintor fray Juan Bautista Maíno, publicó una cédula hallada en el archivo del conde de Orgaz donde el dominico se comprometía a hacer seis pinturas de un retablo costeado por el conde de Castrillo para el monasterio de Espeja, y una cuenta de la misma procedencia donde constan los pagos que se le habían hecho5. Pensó que el retablo estaba destinado a una capilla pequeña de la iglesia y que las pinturas no serían de gran

po de Tuy, visible en la fotografía, al Museo Nacional de Escultura de Valladolid. Ha sido publicada en estudios generales que desconocían la autoría de Crescenzi en su traza, como el de RuBio de La Iglesia, C., San Leonardo de Yagüe. Historia y Cultura, Soria, Ayuntamiento de San Leonardo de Yagüe, 1996. Semanas después de haber entregado este trabajo para su publicación se inauguró la exposición sobre el pintor Juan Bautista Maíno (Prado, 20 de octubre de 2009) cuyo catálogo incluye la fotografía del retablo, menciona al autor de su traza, las fechas de su ejecución y diversos comentarios centrados casi exclusivamente en las pinturas que contuvo (MARÍAs, F., y De CARLos VARONA, M. C., "El arte de las 'acciones que las figuras mueven': Fray Juan Bautista Maíno, un pintor dominico entre Toledo y Madrid", en Juan Bautista Maíno, Madrid, Museo Nacional del Prado, 2009, pp. 57-75; las referencias al retablo y sus pinturas en las páginas 70-71).

2 Agulló y Cobo, M., Documentos sobre escultores, entalladores y ensambladores de los siglos XVI al XVIII, Valladolid, Universidad, 1978, pp. 107-108.

3 Agulló y CoBo, M., Noticias sobre pintores madrileños de los siglos XVI y XVII, Granada, Universidad, 1978, pp. 84-86.

${ }^{4}$ Bartolomé, B., "El conde de Castrillo y sus intereses artísticos", Boletín del Museo del Prado, 33 (1994), pp. 16 y 23.

5 Pérez SÁnchez, A. E., “Sobre Juan Bautista Maíno”, Archivo Español de Arte, 278 (1997), pp. 117-119. Documentos cedidos por Fernando Bouza.

Arch. esp. arte, LXXXIV, 334, ABRIL-JUNIO 2011, 125-138, ISSN: 0004-0428 
tamaño, a pesar de su alto precio. Se interesó principalmente por los comentarios del religioso acerca de los asuntos encargados y su significado en el retablo.

La última aportación se debe a Blanco Mozo, y está incluida en su importante publicación de 2007 sobre el arquitecto Alonso Carbonel, tan estrechamente unido a Crescenzi en su carrera cortesana. Encontró cartas de pago de los doradores Simón López y Miguel de Viveros por el retablo mayor, de López y Crispín Correa por los dos colaterales, de Pedro Núñez del Valle y Luis Fernández por las diez pinturas para estos últimos, del marmolista Juan Francisco Sormano por sus pedestales y de Domingo de Cialceta por la reja de la capilla mayor, dorada por Simón López y Crispín Correa ${ }^{6}$. No mencionó sin embargo la participación de Capitán en la escultura ni de Maíno en la pintura, y aunque advirtió la presencia del arquitecto y ensamblador Bernabé Cordero como testigo en el concierto de Martínez y Cabezón para la talla, no extrajo de ella ninguna consecuencia.

Los diversos autores citados centraron su interés en aspectos parciales, como el mecenazgo del conde de Castrillo, la pintura de Maíno o la arquitectura de Crescenzi. Nuestro estudio se dirigirá, en cambio, a profundizar en las peculiaridades artísticas del retablo en su conjunto con la ayuda de la fotografía que presentamos?

El conde de Castrillo era persona cercana al conde duque de Olivares y protector de Crescenzi y Carbonel, con los que se relacionó continuamente durante los años de la obra del Buen Retiro, en cuya administración y decoración tuvo el conde un papel relevante. No es de extrañar que pidiera al superintendente que trazara su retablo. Las declaraciones que hace Martínez en su escritura de obligación como contratista, otorgada en Madrid el 16 de diciembre de 1634, no dejan lugar a dudas sobre este punto: el retablo se haría "conforme a la traza y planta questá fecha y que está rubricada del señor marqués de la Torre y firmada del dicho señor conde de Castrillo y de mi el dicho Martín Martínez principal y del presente scrivano"8. Como suele ser común en los retablos en que el tracista es uno y el contratista de la obra otro, Martínez declara que se hará "como el dicho marqués de la Torre, de quien está rubricada la dicha traza, lo hordenare y mandare, a cuyo parezer se a de estar y remite en todo lo demás", y en la última condición habla de que "se a de executar y hacer todo lo que está en la dicha traza y planta questá rubricada del dicho señor marqués de la Torre, sin alterar ni mudar ni crezer ni disminuyr cosa ninguna sin horden por escrito del dicho señor marqués de la Torre".

Martín Martínez se obligó en favor de Castrillo a hacer el retablo con las condiciones que constan en el documento, siendo fiadores el carpintero Antonio Rojo y el ensamblador Alberto Ribero, que firmaron junto al obligado principal. Al otorgamiento no concurrió ningún representante de Castrillo, y se dice expresamente que habría de ratificar el documento por su parte, y que en ese momento debería hacer un primer pago a cuenta de 2.000 reales. El retablo debía labrarse en Espeja con madera proporcionada por los frailes, la cual se cobraría al contratista al precio que corriera en aquel lugar, así como el pan, vino y carne y demás mantenimiento y gasto suyo, de su casa y oficiales. El precio total del retablo en blanco, asentado en su lugar, ascendía a 22.000 reales. Además del pago inicial de 2.000 reales, Martínez recibiría 400 reales mensuales durante el año y medio estipulado para su realización, y el resto al finalizar el retablo, menos el importe de la madera y manutención. Lo haría a vista y satisfacción de la persona que designara el conde. Más adelante analizamos las condiciones del retablo en el documento y la forma en que fueron llevadas a la obra.

\footnotetext{
${ }^{6}$ Blanco Mozo, J. L., Alonso Carbonel (1583-1660), arquitecto del Rey y del Conde-Duque de Olivares, Madrid, Fundación Universitaria Española, 2007, pp. 255-256.

${ }^{7}$ Archivo Histórico Provincial de Soria, fotografía n. ${ }^{\circ} 1137$.

8 Véase el Apéndice documental.
} 
El 1 de abril de 1635, en Madrid, Martínez concertó con el entallador Isidro Cabezón de Salas la talla de los elementos decorados: las hojas del pedestal, capiteles, frisos, hojas de canecillos, los dos escudos grandes del remate, tres tarjetas y cuatro festones, y los cuatro tercios de las columnas del remate. Desde el otorgamiento de la obligación de Martínez habían transcurrido apenas tres meses y medio, y Cabezón se comprometía a terminar su parte en un año. A juzgar por las fechas de este contrato, Martínez inició el ensamblaje muy poco tiempo después de obligarse en favor de Castrillo, sin que previera retrasos en la entrega de la obra. Cabezón cobraría por la talla 3.550 reales, en plazos de 100 reales a principios de cada mes durante los 12 meses previstos y el resto al acabar, una vez descontado el importe de su sustento y el de sus oficiales. Entre los testigos estuvo presente el ensamblador Bernabé Cordero.

El dorado del retablo fue contratado de forma independiente de Martínez, quien no se había obligado a dorarlo. La labor de los doradores debió de comenzar antes de que terminara el ensamblador, quien iría dándoles las piezas ya labradas para que las fueran dorando. No se conoce el contrato con los doradores, que fueron Simón López y Miguel de Viveros, dos artífices frecuentemente relacionados con las obras del Rey; el primero llegó a tener título de dorador real. Belén Bartolomé mencionó el nombre del batidor de oro Miguel Manzano en relación con esta obra, seguramente obligado a proporcionar los panes de oro9. Blanco Mozo documentó pagos a los doradores hechos mediante fondos del Consejo de Indias -que quizá se adeudaban a Castrillo- desde 1636 (28 de mayo y 19 de junio) hasta 1638 (27 de marzo $)^{10}$. En el último de estos pagos, que es el finiquito del retablo mayor, consta que el dorado se había convenido en 18.000 reales, un precio relativamente alto respecto al del ensamblaje, si bien hay que considerar que habían de viajar a Espeja.

Otro capítulo fundamental del retablo es el de la imaginería. Bartolomé da noticia de que Jorge Capitán contrató en 1636 una Concepción, un San Jerónimo y un Crucificado para el retablo, dato que debió de conocer en algún documento o cuentas del archivo de Orgaz, pero no da más detalles acerca del encargo. Las dos últimas tallas se distinguen en la fotografía, pero la Concepción había desaparecido para entonces. No sabemos si Capitán hizo también las figuras de la custodia, que entraban dentro de la obligación de Martínez. La figura de Cristo parece de buena factura, lo mismo que la de San Jerónimo con sus atributos. Jorge Capitán está documentado desde principios del siglo. El 27 de agosto de 1602 se obligó a trabajar seis meses en casa del escultor Antón de Morales ${ }^{11}$. En 1605 declaró para Pedro de la Cuadra en el pleito que mantenía contra Francisco del Rincón por el retablo mayor de la parroquial vallisoletana del Salvador ${ }^{12}$. Participó en el pleito de los doradores de $1620^{13}$. En 1625, en que contribuyó con 24 reales en el donativo al Rey, vivía en la calle del Caballero de Gracia ${ }^{14}$. El 30 de mayo de ese año contrató una imagen de San Isidro, dos Virtudes y escudos para el retablo de don Luis Muñoz que estaba haciendo Juan de Echalar ${ }^{15}$. Las figuras del retablo de Espeja son, por ahora, su última obra conocida, si es que realmente las llevó a término por su mano.

\footnotetext{
9 BARTOLOMÉ, cit.

10 Blanco Mozo, cit.

11 PÉrez Pastor, Noticias y documentos relativos a la Historia y Literatura Españolas, Madrid, Imprenta de la Revista de Legislación, 1914, p. 92. BlanCo Mozo, cit., p. 32.

12 Urrea Fernández, J., "Escultores coetáneos y discípulos de G. Fernández, en Valladolid”, Boletín del Seminario de Estudios de Arte y Arqueología, L (1984), pp. 352-353.

13 Blanco Mozo, cit., p. 94.

14 GonZÁlez MuÑoz, M.C., "Datos para un estudio de Madrid en la primera mitad del siglo XVII", Anales del Instituto de Estudios Madrileños, 18 (1981), p. 178.

15 Marín Tovar, C., “Aportaciones para el estudio del retablo barroco madrileño", Madrid, I (1998), pp. 405 y 416-418.
}

Arch. esp. arte, LXXXIV, 334, ABRIL-JUNIO 2011, 125-138, ISSN: 0004-0428 
Por último, Juan Bautista Maíno contrató el 6 de febrero de 1636 seis lienzos para el retablo por 600 ducados. Dos eran apaisados e iban situados en el banco a los lados de la custodia, las prefiguraciones de la Eucaristía el Maná en el desierto y Abraham y Melquisedec o la Cena legal de Cristo $^{16}$, y en los cuerpos primero y segundo y de mayor tamaño, las que se designan por Maíno como cuatro fiestas principales de Nuestra Señora, Natividad de la Virgen, Anunciación, Visitación y Asunción. Los asuntos son perfectamente coherentes con la dedicación a Santa María del monasterio jerónimo. La capilla mayor era de respetables dimensiones, al igual que los cuatro lienzos grandes; de su medida aproximada puede dar idea el sepulcro del obispo de Tuy, de casi 8 metros de alto, por lo que los cuadros tendrían unas 3 varas de alto por 2 de ancho. Según los pagos de que dio cuenta Pérez Sánchez, Maíno recibió 1.000 reales el día del contrato, 2.200 (74.800 maravedís) el 8 de julio, y 1.200 reales el 16 de noviembre, aunque indica al mismo tiempo que los maravedís fueron 74.800, que corresponden a 2.200 reales. Faltarían por pagar 2.200 reales si es correcta la transcripción en reales, ó 1.200 reales si lo fuera la de los maravedís. El finiquito correspondería al pago que se le debió de hacer en marzo de 1637, pues el citado autor indica: "como puede verse, los pagos se escalonan hasta marzo de 1637". Se había obligado a entregar las pinturas el 24 de junio de 1636.

La fotografía muestra sólo dos de los seis lienzos porque los otros cuatro habían sido arrancados. No es demasiado nítida en cuanto a las pinturas, pero la composición se reconoce bien. La Visitación es tradicional, con Santa Isabel y la Virgen acompañada de una criada que llenan casi la altura del lienzo, mientras a la derecha se abre un paisaje urbano de una plaza con torrecillas al fondo, una composición que recuerda a las distintas versiones de Santo Domingo en Soriano con la apertura que deja al descubierto la nave de una iglesia o un retablo. Se observan los rostros delicados y ovales característicos de Maíno. La Asunción sorprende, en cambio, por su movimiento barroco, con los angelotes que sostienen la figura sedente de la Virgen a modo de trono.

La obligación de Martínez indica que el retablo había de llenar la capilla mayor en altura, desde la mesa de altar hasta la bóveda, y en anchura desde los vuelos de las cornisas principales hasta topar con la fábrica de la capilla. La fotografía muestra que así se hizo, si bien ninguna de las cornisas que separaban los cuerpos del retablo coincidía con la del edificio. La capilla mayor del monasterio era muy alta, y, quizá por ello, el presbiterio se situó encima de ocho gradas que

16 PÉReZ SÁnchez, cit., p. 117 y 119, comenta lo extraño de que aparezca una prefiguración de Abraham y una Santa Cena, que no tendría este carácter, y pensó que se trataba de una Cena legal de los hebreos, semejante a la de Tibaldi en el Sagrario de El Escorial. Pero Maíno habla de una Cena legal de Cristo, lo que exige su presencia. El padre Sigüenza llama a esta escena escurialense "El cordero pascual" pero no "Cena legal de Cristo". A nuestro juicio, la explicación puede ser ésta: la cena de Pascua que el Señor ordena preparar de acuerdo con los Sinópticos era la Cena legal de los judíos, con los manjares rituales, en especial, el cordero o cabrito macho asado a fuego, que se comía rápidamente, ceñida la cintura y con un bastón en la mano, tal como ordenó Dios a Moisés. Los exégetas del Nuevo Testamento trataron de conciliar el hecho de que Jesús fuera crucificado el día de la Pascua y la Cena pascual que había celebrado con sus discípulos la víspera, con hipótesis como que, sabedor de su muerte al día siguiente, había anticipado la celebración, o bien la distinción entre el día 14 o nisán en que se comía el cordero y la gran fiesta, que se extendía del 15 al 21 [cfr. Fillion, L. C., Vida de Nuestro Señor Jesucristo, III, Madrid, Rialp, 2000 (primera edición, 1922), pp. 103-105]. La representación de la Cena de Cristo con el cordero pascual encima de la mesa recibiría el nombre de "Cena Legal de Cristo", y constituiría en cierto modo el último episodio de la Antigua Ley y prefiguración de la Eucaristía. La misma última cena, pero con Jesús en el momento de consagrar el pan y el vino sería una institución de la Eucaristía. En la Historia de Nuestro Señor Jesucristo: esposición de los Santos Evangelios de M. J. E. DARRAS, traducida por J. ViCENTE, Madrid, Gaspar y Roig, 1865, p. 629, nota 1022, se explican las discusiones entre los traductores bíblicos acerca de la forma en que se habían sucedido los acontecimientos de la cena pascual de Cristo, y la mayoría de los traductores eran partidarios de situar la institución de la Eucaristía una vez acabada la cena al modo hebreo. 
se extendían de un lado a otro en anchura, disminuyendo así considerablemente el paramento que debía cubrir el retablo, unos 14 por 8 metros. Por encima de un pequeño zócalo de piedra se iniciaba el sotabanco, con recuadros sin decorar limitados por molduras de media caña, muy resaltadas en la fotografía por algún dorado o pintura reciente. No se aprecia la mesa de altar, que seguramente habría desaparecido para entonces. El banco del primer cuerpo tiene una altura que coincide aproximadamente con la de la puerta del sagrario y muestra los huecos para las dos prefiguraciones eucarísticas, enmarcadas por medias cañas, y los plintos de las columnas de las calles laterales y central -estos últimos mucho más adelantados- ornados con espejos de factura bastante simple. En el centro del cuerpo inferior se abría una gran caja con remate de punto redondo, flanqueada por dos columnas superpuestas a otras dos interiores, y en el hueco se disponía el tabernáculo. Las dos columnas sobresalientes eran soportadas por sendas cartelas de hojas que reposaban en el banco, como prescribía el contrato. A los lados de este primer cuerpo quedaban los huecos donde estuvieron los lienzos de la Natividad de la Virgen y la Anunciación, con marcos de gallones, codillos en los cuatro ángulos y unos remates superiores de tarjetas flanqueadas por festones de frutas. Las columnas de este cuerpo eran del orden corintio con fustes estriados todas ellas y tenían retropilastras con sus capiteles y basas. Encima se extendía el entablamento, con un friso decorado con cogollos y una cornisa con dentellones, siguiendo la línea quebrada de los salientes y entrantes del cuerpo inferior. Sobre el cuadro central se elevaba -sin romper la continuidad del entablamento aunque tapando parte del pedestal del segundo cuerpo- un frontispicio curvo, no quebrado como establecía el contrato, con una gran tarjeta interior que invadía la cornisa dentellada, rompiéndola aparentemente. El segundo cuerpo tenía una altura semejante a la del primero. Se componía de una basa con recuadros relevados de tarjetas y roleos bajo los lienzos y pedestales de las columnas; la caja central para la escultura de la Concepción -que no aparece ya en la fotografía- remataba en medio punto, con marco rectangular de doble media caña y albanegas decoradas, y rompía el arquitrabe del cuerpo intermedio hasta el friso; a los lados, dos columnas avanzadas sobre el plano, en correspondencia con las del cuerpo principal. Los marcos de los lienzos del segundo cuerpo eran semejantes a los del primero, aunque sin la tarjeta y guirnaldas superiores, y las columnas corintias tenían fuste entorchado. Por encima, un entablamento corrido en todo semejante al del primer cuerpo. El piso superior se componía de una caja central también acabada en medio punto, aparentemente del mismo tamaño que la del cuerpo segundo, con dos columnas a los lados y otras dos adelantadas, todas ellas corintias con plintos labrados, el primer tercio de talla y fustes entorchados. Encima, un arquitrabe y friso rotos por la caja, y un gran copete formado por frontón curvo con su cornisa de dentellones y en el interior un florón central de poco relieve y las enjutas talladas. En la caja estaba Cristo crucificado y a sus pies, San Jerónimo penitente golpeándose el pecho con una piedra, un libro abierto sostenido por una calavera bajo la cruz, al otro lado una rama con el capelo cardenalicio y el manto y el león recostado más abajo. A los lados de la caja, los dos grandes escudos del patrono con follaje y guirnaldas sobre unos pedestales unidos por aletones al cuadro central, y en los extremos dos pirámides.

La custodia repetía las estructuras del retablo y llenaba la caja del primer cuerpo en anchura y altura. Sotabanco y banco, que apenas se ven en la foto, debían de ser simples, con una media caña alrededor. Tenía dos cuerpos de forma poligonal en disminución y en correspondencia uno con otro, seguramente medios ochavos adosados a la caja inferior del retablo. El contrato ordenaba que las columnas del primer cuerpo del tabernáculo fueran estriadas y las del segundo entorchadas - del mismo modo que en el retablo-, y las pilastras vaciadas con una media caña y con basas y capiteles como los de las columnas; estos detalles no se distinguen en la fotografía. El cuerpo inferior tenía una gran puerta de medio punto y encima un frontón semicircular, una estructura que parece reproducirse en los laterales. Quizá en esas puertas había figuras labradas y parece que hay piñas sobre la cornisa. El segundo cuerpo tenía recuadros con orejetas y remataba en cornisa lisa. En la parte superior es visible la media naranja prevista en el contrato, y 
delante de ella y alzándose sobre los lados del segundo cuerpo se observan los nichos que especificaban las condiciones.

Blanco Mozo se preguntó sobre la novedad del retablo y, no conociendo la fotografía, concluyó que radicaba principalmente en la mayor altura del pedestal. No observó innovaciones en la articulación del alzado, pero sí en la decoración, que consideró más profusa de lo ordinario, y remarcó la similitud de los recursos de Crescenzi -menos acostumbrado al arte del retablo- con los de Carbonel, derivados de las últimas soluciones del manierismo romano e hispano, respectivamente.

En nuestra opinión, este retablo no presenta novedades en su estructura. Tampoco en lo decorativo se observan diferencias importantes con otros retablos de la época, ni en los motivos ni en su colocación. Aparecen roleos adornando los frisos, cardina en las albanegas, una gran tarjeta en el frontón central y otras menores en los tableros encima de los lienzos del primer cuerpo $\mathrm{y}$ en los plintos de las columnas situados en el banco, recursos comunes a otros arquitectos. Consideramos originales para el arte cortesano del momento los marcos acodados de los cuatro lienzos, pues, aunque Blanco Mozo recuerda que se hacían en ese mismo momento los de la fachada del Colegio Imperial de Madrid y, poco después, eran utilizados por Carbonel en la fachada de las dominicas de Loeches, los modelos son muy distintos: en el Colegio son incipientes orejetas en la parte superior, mientras en Espeja son unas desarrolladas cantoneras en las cuatro esquinas. En cambio las encontramos en Loeches, no en la fachada, sino en la portada del crucero de la iglesia, posterior en varios años al retablo que estudiamos. Otro elemento destacable es la ruptura de la continuidad del friso del segundo y del tercer cuerpo al llegar a las columnas, pues los cogollos de su decoración se transforman en dos hojas carnosas de distinto diseño.

$\mathrm{El}$ arquitecto destaca de modo ingenioso y variado algunas partes del retablo respecto a otras. En lo vertical, la calle central gana presencia en altura gracias a una creciente decoración hasta culminar en la caja superior, sumamente potente y adornada. Los fustes de las columnas son estriados en el primer cuerpo, entorchados en el segundo, y entorchados y con el tercio inferior tallado en el cuerpo superior; además, la articulación de las cajas centrales con el entablamento es cada vez más violenta y transgresora del orden clásico: en el primer cuerpo, el entablamento queda intacto, el del segundo cuerpo pierde el arquitrabe por entrar en él la caja de la Virgen, y en el tercer cuerpo el nicho central penetra en arquitrabe y friso para detenerse solamente a la altura de la cornisa. En lo horizontal, rompe la regularidad del ancho y alto de las calles con la ilusión óptica de que la central es más ancha -solo aparentemente- al hacerla resaltar con unas columnas dobladas que se prolongan sucesivamente hasta la caja superior, sostenidas en el banco inferior por grandes cartelas.

Crescenzi empleó aquí recursos a los que había acudido anteriormente, como los cogollos del friso, no entrelazados y de gran relieve, ya presentes de manera incipiente en el Panteón del Escorial. Conviene anotar al respecto que aunque los especialistas han atribuido su aparición a Crescenzi, al menos se ven en la forma de Espeja ya en el retablo de Algete, trazado por Juan Muñoz en 1612. También tienen los sarcófagos escurialenses una gran tarjeta parecida a la que decora el frontón del primer cuerpo. El adorno de los escudos, de los pedestales del segundo cuerpo y del remate sigue bastante literalmente los del sepulcro de la emperatriz María en las Descalzas Reales de Madrid ${ }^{17}$.

Se ha discutido mucho la autoría de la Cárcel de Corte $^{18}$. El edificio, trazado en 1629 y atribuido por Tovar a Gómez de Mora, en lo que estamos de acuerdo con matices, debía de estar

17 Atribución de Cé́n Bermúdez, J. A., Diccionario..., Madrid: Viuda de Ibarra, 1800, t. I, p. 375, argumentada convincentemente por BlANCO Mozo, cit., pp. 139-141.

${ }_{18} \mathrm{Al}$ margen de las fuentes clásicas, véase TAYLOR, R., "Juan Bautista Crescencio y la arquitectura cortesana española (1617-1635)" en Academia, 48 (1979), p. 91, que atribuyó el edificio a Alonso Carbonel, y percibía solamente una hipotética participación de Crescenzi en el mascarón de la puerta principal y en los del doble patio; TOVAR MarTín, V., "La Cárcel de Corte madrileña: Revisión de su proceso constructivo", Revista del Archivo, Biblioteca y Museo, 7 (1980), p. 7. 
avanzado en su construcción cuando Crescenzi, nombrado superintendente de las obras reales en 1630, pudo empezar a intervenir. Finalizado en 1634 según decía la inscripción de su portada, opinamos que al romano le quedarían tan sólo algunos aspectos decorativos que pudieran añadirse a lo hecho, fundamentalmente la portada, y tal vez el remate de los patios decorados con unas hermas con mascarones. Comparando la portada con el retablo de Espeja, es posible reconocer en ambos diseños la misma forma de estructurar las tres calles, con la central resaltada frente a las laterales mediante dobles columnas superpuestas. Los tarjetones de los vanos inferiores de la Cárcel, muy similares a los del Panteón, tienen algún parecido con el que decora el frontón sobre la custodia del retablo, a pesar de que, en este punto, Cabezón de Salas no siguió escrupulosamente las condiciones de su contrato; en cambio, la tarjeta del INRI que corona la cruz del grupo escultórico de Jorge Capitán es idéntica. Los codillos de la ventana central del segundo cuerpo del edificio tienen unas orejetas menos acusadas que en Espeja, pero del mismo modelo. La ruptura del entablamento en la calle central de la Cárcel a la altura del segundo cuerpo, con invasión del espacio por el gran escudo del coronamiento, logra un resultado estético parecido al del retablo cuando interrumpe las líneas de los entablamentos. Tantas similitudes se explicarían si fueran obras del mismo tracista, tanto más tratándose de diseños coetáneos, y las diferencias no son relevantes a este respecto: la utilización del orden dórico en la Cárcel y del orden corintio en el retablo deriva de la distinta función, y la terminación triangular de la primera y semicircular del segundo se deben al diferente marco para el que se destinaban. Para una arquitectura en piedra, estas bizarrías eran incluso más complicadas e inusuales que en un retablo de madera, lo que induce a pensar, a falta de confirmación documental, en Crescenzi, tracista poco vinculado a los aspectos prácticos de la construcción. Finalmente advertimos que el adorno de la Cárcel con escudo real y con estatuas que contrató Antonio de Herrera, escultor del rey, sigue el esquema que dispuso ya Crescenzi en la portada del Alcázar, trazada en 1619, aunque en esta última obra no se llegaron a poner las esculturas, que irían debajo del escudo real y tal vez en el frontispicio ${ }^{19}$.

Para valorar en su justa medida lo que representa el retablo de Espeja en el panorama madrileño del momento, disponemos de un punto de comparación adecuado, que es la traza coetánea de Gómez de Mora para el mayor del hospital madrileño de Antón Martín, conservada en el

${ }^{19}$ Crescenzi cobró 200 ducados en una libranza de 22 de febrero de 1619 por un modelo del pórtico y 16.188 maravedís el 2 de abril por una traza para el mismo, publicadas respectivamente por MARÍAS, F., "De pintores-arquitectos: Crescenzi y Velázquez en el Alcázar de Madrid", en Velázquez y el arte de su tiempo, Madrid, CSIC, 1991, p. 83, y Blanco Mozo, J. L., cit., p. 163. Aunque ambos autores dejaron abierta la posibilidad de que la traza de Crescenzi no se siguiera, el primero de ellos reconoció su estilo en la portada, desaparecida pero conocida por diversos testimonios gráficos y la maqueta depositada por el Museo Arqueológico Nacional en el Museo de Historia de Madrid. Por nuestra parte añadimos que se trata de un diseño con elementos típicos de los palacios romanos del Manierismo final como la fachada del propio palacio Crescenzi, proyectada por el protegido de la familia Nicolò Sebregondi; cuenta con balcón destacado y adorno de festones como el Alcázar. Además muestra unas ménsulas iguales a las del Panteón o el nicho del coro de las Descalzas Reales. Por otro lado hay que tener en cuenta que se hizo un modelo de la portada de Palacio según la traza de Crescenzi por orden del rey transmitida al arzobispo de Burgos, don Fernando González de Acevedo, como presidente del Consejo de Castilla. González de Acevedo era conocedor de la capacidad de Crescenzi por su dirección de la obra del trascoro de la catedral de Burgos. Probablemente fue quien promovió la entrada de Crescenzi en las obras reales, hasta entonces dirigidas exclusivamente por Gómez de Mora, encargándosele al mismo tiempo - una simultaneidad que hasta el momento no parece que se haya puesto de relieve- un modelo para el interior del Panteón, cuya hechura cobraron sus autores materiales en octubre y noviembre de 1618, al mismo tiempo que el de la portada (vid. Martín GonzÁlez, J. J., "Arte y artistas del siglo XVII en la Corte", Archivo Español de Arte, 31 (1958), p. 129, y Blanco Mozo, cit., p. 163). Finalmente señalamos que Ludovico Turchi ofreció dos esculturas de Marte y Palas, de diez pies de alto para la portada del Alcázar, y a pesar de estar previstas tallas a los lados de la ventana bajo el escudo real, se desecharon por no caber en los huecos (Martín GonZÁlez, J. J., El escultor en Palacio: Viaje a través de la escultura de los Austrias, Madrid, Gredos, 1991, pp. 164-165).

Arch. esp. arte, LXXXIV, 334, ABRIL-JUNIO 2011, 125-138, ISSN: 0004-0428 
Museo del Prado. Atribuida generalmente a Alonso Cano, Marías la restituyó al maestro mayor de las obras reales ${ }^{20}$, aunque con alguna reserva, que nosotros no tenemos. El diseño corresponde en todo a las precisiones contenidas en el contrato que celebró el ensamblador Juan de Echalar el 25 de julio de 1633, en que se decía que la traza era de Gómez de Mora. La comparación revela una estructura semejante: pedestal de piedra y banco de madera de poca altura, tres cuerpos de columnas de orden corintio dobladas por traspilastras, custodia ocupando enteramente el nicho del primero y remate de frontispicio redondo flanqueado por escudos. La imaginería se compone de cuatro lienzos en los dos primeros cuerpos y en lo alto una figura del Crucificado con la Virgen y San Juan de escultura, y debajo la imagen antigua de Nuestra Señora del Amor de Dios, que era la advocación del Hospital. A pesar de la identidad de estructuras, el aspecto general de ambos retablos resulta diferente como consecuencia de que el maestro mayor optó por incluir el cuerpo superior en un cerchón semicircular, rellenando las enjutas con tableros que incluían, superpuestos, los escudos, mientras Espeja mantiene una solución más tradicional y menos acorde con la moda madrileña del momento, al dejar exentos la caja, los escudos y las pirámides. Tampoco existen en el retablo madrileño las basas decoradas que Crescenzi dispuso bajo los lienzos del segundo y tercer cuerpo, que añaden complejidad a la visión general del retablo, en tanto que el madrileño ofrece un aspecto más sobrio. En el mismo sentido opera la ausencia de las dobles columnas en la calle central, que confiere al retablo mayor serenidad.

La decoración es abundante en ambos retablos y está emplazada en los mismos lugares. Las tarjetas del retablo madrileño son vegetales frente al tipo de placa recortada que prevalece en el soriano; los destacados codillos de los marcos de Crescenzi apenas son leves quiebros en el diseño de Gómez de Mora. Es común a ambos la rotura de los entablamentos del frontispicio, si bien Gómez de Mora prescinde incluso de la cornisa y hace entrar de lleno al Crucificado en el espacio que hubiera debido ocupar el frontón con un marco quebrado. En el retablo de la orden hospitalaria los frisos se decoran, como era habitual, con roleos entrelazados y de menos relieve que los de Espeja. Gómez de Mora conserva en los tres cuerpos el mismo tipo de columnas -estriadas con tercio inferior machihembrado-, a diferencia de Crescenzi, que varía la forma del fuste en cada cuerpo.

En resumen, nos encontramos ante el único retablo ideado por Crescenzi cuya imagen ha llegado a nuestros días, en que se puede comprobar las peculiaridades de su estilo lleno de recuerdos manieristas, tan diferente del de Gómez de Mora. Es digno de destacar que esta obra vuelve a reunir a Crescenzi y Maíno, los jueces que dieron vencedor a Velázquez en el concurso de 1627 entre los pintores reales. El conde de Castrillo llamaría a Maíno admirado por su pintura de la Recuperación de Bahía para el Salón de Reinos, pero sería bueno preguntarse si el marqués de la Torre se lo había recomendado antes de morir en marzo de 1635, como probablemente sucedió con otro pintor apreciado por el italiano, Antonio Pereda, respecto al retablo de la parroquial madrileña de San Miguel, trazado por el italiano para el cardenal Zapata ${ }^{21}$.

\footnotetext{
${ }^{20}$ Marí́As, F., "Alonso Cano y la columna salomónica" en Figuras e imágenes del Barroco, Madrid, Fundación Argentaria-Visor, 1999, p. 291.

${ }^{21}$ Cherry, P., "La intervención de Juan Bautista Crescenzi y las pinturas de Antonio de Pereda en un retablo perdido (1634)", Archivo Español de Arte, 239 (1987), pp. 299-305. Este autor y Blanco Mozo no dan por seguro que el retablo fuera trazado por el marqués de la Torre, lo que nos parece indudable a la vista de los términos usados en el contrato con Pedro de la Torre para su hechura. Queremos señalar el hecho hasta ahora inadvertido de que el retablo contuvo una custodia de bronce y piedras preciosas valoradas en 6.000 ducados que envió Zapata desde Roma (MESONero Romanos, R., El Antiguo Madrid, Madrid, Mellado, 1861, t. I, p. 71). Se sabía que Lope de Vega la elogió en un soneto pero no se había dado explicación satisfactoria del destino de esta obra, confundida en alguna ocasión con el tabernáculo de Montini hoy en Palacio Real (vid. GonzÁlez Palacios, A., "Un adornamento vicereale per Napoli” en Civiltà del Seicento a Napoli, Nápoles, Electa, 1984, vol. II, p. 249. Resolvió el error MarTínez Del Barrio, J. I., Mecenazgo y política cultural de la casa de Osuna en Italia (1558-1694), tesis doctoral inédita, Madrid, Universidad
} 
No sabemos que se haya comentado la presencia de Alberto Ribero como fiador en el contrato de Martín Martínez, ni la de Bernabé Cordero como testigo de la escritura de Isidro Cabezón de Salas, a pesar de que se trata de dos de los más importantes arquitectos de retablos del momento en Madrid. Su concurrencia no parece casual. En el primer caso, pensamos que sería difícil encontrar quien quisiera trasladarse a un lugar tan alejado como Espeja, y Crescenzi hubo de aceptar a Martínez, un artífice de poco nombre, que vendría recomendado por Ribero, con quien habitualmente colaboraría; Crescenzi debió de exigir la fianza de Ribero para consentir en que se hiciera cargo de una obra para un cliente de tanta categoría. Respecto a la presencia de Cordero junto a Cabezón de Salas, podría significar que este entallador pertenecía al círculo de sus colaboradores.

Aunque no se ha advertido por los investigadores del panorama artístico burgalés y soriano, el ensamblador Martín Martínez que hizo el retablo de Espeja ha de ser el mismo que trabajó en tierras del obispado de Burgo de Osma desde 1635 hasta al menos $1668^{22}$. A la vista de sus obras conocidas, este ensamblador aprovechó el modelo de Espeja para los encargos parroquiales que le fueron llegando por su cargo de maestro del obispado de la diócesis oxomense. Su prestigio crecería al amparo del éxito de su obra para el monasterio jerónimo, y a partir de ese diseño, propagó el estilo de Crescenzi en toda la zona: columnas estriadas, entorchadas y con el tercio de talla, frisos con cogollos, cartelas en las columnas inferiores centrales, codillos, festones sobre los cuadros, y tarjetas, siguiendo con fidelidad y escaso genio artístico lo que había hecho bajo el diseño del italiano.

Los retablos colaterales de Espeja desaparecerían de la iglesia al mismo tiempo que el mayor, pues se advierte su presencia en la fotografía que analizamos. No parece que se haya conservado su imagen. Su tamaño era grande, unos dos tercios de la altura del mayor, como demuestra el extremo de la cornisa del colateral izquierdo que se entrevé en la fotografía. Se sabe que se doraron poco después del retablo mayor, y que lo hicieron Simón López y Crispín Correa -Miguel Viveros había muerto- con pagos registrados entre el 24 de julio de 1638 y 27 de septiembre de 1640 por precio total de 15.000 reales, lo que confirma su buen tamaño. Los 10 lienzos que contenían corrieron por cuenta de Pedro Núñez del Valle -cuñado de Carbonel- y Luis Fernández desde el 6 de junio de 1637, en que cobraron los primeros 2.000 reales de los 8.000 totales. Conocemos cuatro de los asuntos que se nombran en el inventario redactado por el cura de San Marcelino en $1821^{23}$ : en los respectivos cuerpos principales iban un San Jerónimo en el del evangelio, y la Virgen, san Juan y santa Catalina en la epístola; en los remates San José y Santa Teresa, en lo que parece una iconografía carmelita o simplemente una muestra de devoción de los condes a dos santos de culto muy extendido en ese momento. Los otros seis cuadritos irían dos en los sagrarios y dos parejas flanqueándolos en los pedestales. Además había dos urnas con reliquias en cada retablo; las de san Marcelino, que dieron nombre al pueblo, y las de san Diodoro, actualmente en la parroquial de la vecina localidad de Guijosa. Juan Francisco Sormano hizo los pedestales de mármoles y cobró 6.700 reales, el 29 de mayo de 1637 , de los 37.800 en que se pactó su precio, que comprendía el solado y gradas. El carpintero Antonio Rojo que cita Bartolomé pudo hacer tal vez los frontales de madera o la cajonería. No es probable que su traza se debiera a Crescenzi, fallecido el 10 de marzo de 1635, sino a

Complutense, 1991, vol. I, p. 231. Citado por García Cueto, D., "Presentes de Nápoles. Los virreyes y el envío de obras de arte y objetos suntuarios para la Corona durante el siglo XVII", en España y Nápoles. Coleccionismo y mecenazgo virreinales en el siglo XVII, Madrid, Centro de Estudios de Europa Hispánica, 2009).

22 Arranz Arranz, J., La escultura romanista en la diócesis de Osma-Soria, p. 191; Zaparain YÁÑez, M. J., "Martín Martínez arquitecto y escultor de la diócesis de Osma. 1646-1668. Aproximación a su obra" en Actas del I congreso de jóvenes historiadores y geógrafos, Madrid, Universidad Complutense, 1990, pp. 221-230.

23 ZAMORA LUCAS, cit. 
Carbonel, su principal colaborador y hombre de la confianza de Castrillo. De su hechura debió de ocuparse también Martínez.

Para concluir haremos referencia a la gran reja que servía de cierre al presbiterio, obra, como se sabe, del famoso artífice Domingo de Cialceta, que recibió por ella pagos el 6 de junio de 1637, y el 11 de agosto, 14 de septiembre, 2 y 26 de octubre de 1638. La libra de hierro labrada se le pagó a 2 reales y 12 maravedís. Fue dorada por López y Correa -que doraron también la barandilla del presbiterio-, y Sormano hizo su pedestal, como se señala en los pagos a cuenta de los colaterales. Aunque su obra se desarrolla con preferencia en Madrid y localidades en el entorno de Alcalá de Henares y Sigüenza, la importancia del comitente y la dificultad del encargo haría imposible que se hiciera a algún rejero de localidades más próximas a Espeja. La reja se componía de un cuerpo principal de barrotes en cuyo centro estaba la puerta de doble batiente, friso, cornisa y remate de tornapuntas con jarrones y fruteros que enmarcaban el escudo del comitente, resaltado por dos festones y tornapuntas elevadas. Se trata de un ejemplar de gran calidad cuyos motivos son propios de la platería.

\section{6-12-1634. Contrato para el retablo mayor de Espeja. A.H.P.M. Prot. 4.827, fol. 1259-1262v.}

Sepan quantos esta carta de obligación bieren como nos, Martín Martínez, maestro de ensanblador, vecino de la villa de Madrid, como prinzipal, y Alverto Rivero, maestro de ensanblador, y Antonio Rrojo, maestro de carpintería...otorgamos y conocemos por esta presente carta que nos obligamos en favor del señor don Garzía de Haro, conde de Castrillo y presidente del qonsejo de las Yndias de su majestad, y de quien su poder y derecho huviere, de hazer y que yo el dicho principal aré y haremos a toda costa de manos, madera y oficiales un retablo para el altar mayor de la capilla mayor de la yglessia y conbento de San Gerónimo de Espeja, que es del dicho señor conde, de madera de pino seca y limpia y de vuena ley, que a de tener tres cuerpos y su custodia en medio en el primer cuerpo, conforme a la traza y planta questá fecha y que está rubricada del señor marqués de la Torre y firmada del dicho señor conde de Castrillo y de mi el dicho Martín Martínez principal y del presente scrivano en la forma y con las calidades y condiciones siguientes:

Condiciones: - Primeramente el dicho retablo a de enllenar la capilla mayor de la dicha yglesia en ancho y alto, en quanto a lo alto se entiende a de ser de la mesa del altar asta topar con la vóveda, y en quanto a lo ancho los vuelos de las cornisas principales an de topar con la fávrica de la dicha capilla.

-Yten que los pedestales del retablo an de ser apeynazados con una media caña o jalón, y la vasa y sotavasa a de llevar las molduras conforme está en la traza, con la que conviniere según de la horden que fueren, como el dicho marqués de la Torre, de quien está rubricada la dicha traza, lo hordenare y mandare, a cuyo parezer se a de estar y remite en todo lo demás, los quales dichos pedestales an de ser sus molduras eligidas y no aplacadas.

-Yten se an de hacer en el pedestal dos cartelas con sus oxas muy vien hechas.

-Yten que las colunas del primero y segundo cuerpo y remate an de ser y las haremos güecas, porque con la fuerça del corazón de la madera no avran, y las del primer cuerpo an de ser estriadas y las del segundo entorchadas.

- Yten todas las pilastras del dicho retablo se an de hacer y las haremos de tablones que tengan todo el grueso y no lleven piezas por la parte de atrás.

- Yten las dichas pilastras y muros del primero y segundo cuerpo y remate an de llevar sus capiteles y vasas y an de atar con las de las colunas conforme lo muestra la planta.

-Yten los quadros del primero y segundo cuerpo an de llevar agallones y trelixos, y con contarios y codillos conforme en la traza se muestran, y se an de hacer sus tableros para detrás de las pinturas.

-Yten se an de hacer encima de los cuadros del primer cuerpo unas tarxetas y a los lados unos festones de talla conforme lo muestra la traza. 
- Yten las cornisas del primero y segundo cuerpo an de ser y las haremos talladas de óbalos y dentellones, y los alquitraves an de tallar los miembros que en la traça están tallados, y los frisos se an de hacer de talla muy vien hechos.

- Yten se a de hacer y haremos en la cornisa del primer cuerpo un frontispicio quevrado, y en medio una tarxeta conforme lo muestra la traza.

- Yten en el segundo cuerpo se ha de hacer y haremos un quadro tallado con cortezas y trelifos y quentas.

- Yten que en el dicho quadro se a de romper el alquitrave y a de llegar al friso, y dentro dél se a de hacer una caja conforme en la traza se muestra.

- Yten es condición que se an de hacer y que haremos dos escudos con unas guirnaldas en que asienten y dos pirámides conforme la traza lo muestra.

- Yten en el rremate se a de hacer y haremos una caxa redonda que llegue asta la cornisa, y en las colunas del remate se an de hacer tercias de talla y las dos tercias entorchadas, y encima de la cornisa se a de hacer un frontispicio redondo resalteado con que remate toda la obra.

- Yten que en la dicha obra no ha de aver ni llevar ninguna cosa aplacada, que todo a de ser eligido y ser ensamblado como se acostumbra a hacer en semejantes obras.

- Yten que la dicha custodia del dicho retablo a de enllenar la caxa de ancho y alto, y los pedestales an de ser con sus vaciados y una media caña alrededor, y su vasa y sotavassa como en la traza se muestra.

- Yten las colunas del primer cuerpo de la dicha custodia an de ser estriadas y las del segundo cuerpo entorchadas, y las pilastras an de ser vaciadas con una media caña y an de llebar vasas y capiteles conforme las colunas los llevaren.

- Yten la cornisa del primero y segundo cuerpo de la dicha custodia se an de tallar óbalos y dentellones y cuentas en los alquitraves y frisos de talla.

- Yten en el remate de la dicha custodia se a de hacer y haremos una media naranja y una hurnia encima de la dicha media naranja.

- Yten hemos de hacer y haremos todas las figuras de la dicha custodia toda ella de buena madera seca y limpia, que no aya de aver en ella ninguna cosa sobrepuesta sino todo elijido y muy vien ensamblado.

-Yten es condición que se a de executar y hacer todo lo que está en la dicha traza y planta questá rubricada del dicho señor marqués de la Torre, sin alterar ni mudar ni crezer ni disminuyr cosa ninguna sin horden por escrito del dicho señor marqués de la Torre.

- En la qual dicha forma... le asentaré y daré asentado en el dicho altar de la capilla mayor de la dicha yglesia, el qual haré y he de hacer en el dicho conventto de Espeja donde le he de yr a lavrar... y toda la madera que fuere necesario para hacerle me la an de dar los frayles...y... todo el pan, vino y carne y demás mantenimiento que hubiere menester para el gasto de mi persona, casa y oficiales al precio que passare en la dicha villa... y que yo el principal le haré a toda costa como dicho es por precio y quantía de veinte y dos mill reales...en esta villa de Madrid a diez y seis días del mes de diciembre de mill y seiscientos y treinta y quatro años, siendo testigos Gregorio de la Peña, Gabriel Rivero y Feliverto Biçarro, estantes en esta dicha villa, y los dichos otorgantes que yo el scribano doy fe que conozco lo firmaron. Martín Martínez. Alberto Rivero. Antonio Rojo. Pasó ante mi, Francisco Rodríguez.

Fecha de recepción: 2-X-2009

Fecha de aceptación: 25-III-2010

Arch. esp. arte, LXXXIV, 334, ABRIL-JUNIO 2011, 125-138, ISSN: 0004-0428 